Original article

\title{
Sexting Among Young Adults
}

\author{
Deborah Gordon-Messer, M.P.H. ${ }^{a}$, Jose Arturo Bauermeister, M.P.H., Ph.D. ${ }^{\text {b,* }}$, \\ Alison Grodzinski, M.L.I.S. ${ }^{a}$, and Marc Zimmerman, Ph.D. ${ }^{c}$ \\ a Prevention Research Center of Michigan, University of Michigan School of Public Health, Ann Arbor, Michigan \\ b Sexuality \&' Health Lab, Department of Health Behavior and Health Education, University of Michigan School of Public Health, Ann Arbor, Michigan \\ ${ }^{\mathrm{c}}$ Department of Health Behavior and Health Education, University of Michigan School of Public Health, Ann Arbor, Michigan
}

Article history: Received January 6, 2012; Accepted May 15, 2012

Keywords: Young adults; Text messaging; Sexual behavior; Mental health

\section{See Related Editorial p. 257}

\section{A B S T R A C T}

Purpose: Sexting has stirred debate over its legality and safety, but few researchers have documented the relationship between sexting and health. We describe the sexting behavior of young adults in the United States, and examine its association with sexual behavior and psychological well-being.

Methods: Using an adapted Web version of respondent-driven sampling, we recruited a sample of U.S. young adults (aged $18-24$ years, $N=3,447$ ). We examined participant sexting behavior using four categories of sexting: (1) nonsexters, (2) receivers, (3) senders, and (4) two-way sexters. We then assessed the relationships between sexting categories and sociodemographic characteristics, sexual behavior, and psychological well-being.

Results: More than half (57\%) of the respondents were nonsexters, $28.2 \%$ were two-way sexters, $12.6 \%$ were receivers, and $2 \%$ were senders. Male respondents were more likely to be receivers than their female counterparts. Sexually active respondents were more likely to be two-way sexters than non-sexually active ones. Among participants who were sexually active in the past 30 days, we found no differences across sexting groups in the number of sexual partners or the number of unprotected sex partners in the past 30 days. We also found no relationship between sexting and psychological well-being.

Conclusions: Our results suggest that sexting is not related to sexual risk behavior or psychological well-being. We discuss the findings of this study and propose directions for further research on sexting.

(C) 2013 Society for Adolescent Health and Medicine. All rights reserved.

\section{IMPLICATIONS AND} CONTRIBUTION

We investigated sexting behavior among young adults in the United States using four categories: nonsexters, receivers, senders, and twoway sexters. Our findings provide evidence that sexting is prevalent among young adults, but does not appear to be related to sexual risk or psychological well-being.
Sexting, which describes sharing sexually suggestive photos or messages through cell phones and other mobile media [1], is rapidly becoming part of the dating process [2]. Recently, this behavior has stirred substantial concern over its legality and

\footnotetext{
* Address correspondence to: Jose Arturo Bauermeister, M.P.H., Sexuality \& Health Lab, Department of Health Behavior and Health Education, University of Michigan School of Public Health, 1415 Washington Heights, 3822 SPH I, Ann Arbor, MI 48109.

E-mail address: jbauerme@umich.edu (J.A. Bauermeister).
}

safety $[3,4]$. Although existing surveys document the prevalence among young adults (YAs) and demographic characteristics associated with sexting, there is little systematic research on the relationship between sexting and health behaviors commonly assumed to be linked to sexting (e.g., mental health, sexual behaviors). It is critical to understand this relationship to determine whether and how public health resources should be devoted to sexting.

Since 2009, cross-sectional studies have examined the prevalence of sexting behavior among teens and YAs [2,5-7]. Most 
recently, Lenhart [7] found that $13 \%$ of those aged 18 to 29 years had sent sexually suggestive nude or seminude images via cell phones and 31\% had received these messages. Researchers also found that men were more likely to have received sexts (21\%) than women (11\%), and African American and Hispanic adults had higher odds of receiving sexts ( $27 \%$ and $22 \%$, respectively) than whites (12\%). Frequent users of cell phones and social networking technology and single adults reported sexting more than low-technology users or married adults [7].

In an MTV-sponsored study, researchers found that $45 \%$ of youth (aged 14-24 years) who reported having sex in the past week also reported sending at least one sext [5]. They also found that sexually active youth were twice as likely to share naked photos compared with their non-sexually active peers [5]. Although informative, these findings do not elucidate whether sexting is related to self-reported sexual risk behaviors. Researchers have proposed three perspectives regarding the relationship between sexting and sexual behavior: (1) sexting may lead to risky sexual behaviors such as early sexual initiation and less contraceptive use [8], (2) sexting may be a safer sex behavior if it is used in lieu of physical contact [2], or (3) sexting may reflect a new medium for the long-standing practice of photo sharing in romantic and sexual relationships and have no association with safer or riskier sex behaviors [1]. It is vital to understand how sexting is related to sexual behaviors, as it could be promoted as a safer sex behavior or become a focus of intervention to prevent risky sexual behavior.

Media reports and scholars have also proposed a relationship between sexting and psychological well-being [9-11]. Some researchers suggest that mental health is connected to youth's motivation to sext. People with social anxiety may prefer texting to voice calls as a medium for intimate contact, and may also prefer sexting as a medium for sexual contact $[4,12]$. Other researchers and the media raise concern over the psychological consequences of sexting. The spread of sext messages beyond the original recipient and pressure to sext are both common occurrences $[5,6]$ and may be related to subsequent psychological distress $[3,13]$. In addition, a number of dating violence education programs have included unwanted text and sext messages in their definitions of dating violence $[12,13]$. To date, researchers have not tested the relationship between sexting and symptoms of psychological well-being directly. The absence of such data is a concerning gap in our understanding, given that if sexting is related to adverse mental health, intervention is critical to prevent or mitigate negative outcomes.

\section{Study Goals and Objectives}

Our study has three goals. First, we describe the prevalence of sexting in a large national sample of 18-24-year-old YAs in the United States. We break sexting into four categories: (1) nonsexters (neither sent nor received a sext), (2) senders (sent but never received a sext), (3) receivers (received but never sent a sext), and (4) two-way sexters (both sent and received a sext). Second, we examine whether participants who engage in different sexting behaviors differ in their sociodemographic characteristics. Finally, we test the association between YAs' sexting behaviors, sexual behavior, and psychological well-being. We discuss the implications of sexting for YAs and suggest directions for both research and practice.

\section{Methods}

Sampling

Participants were recruited using a Web-based respondentdriven sampling (RDS) strategy [14]. To be eligible for the study, respondents had to be aged between 18 and 24 years, live in the United States, and have access to the Internet. The first wave of participants (seeds) was recruited through an online Facebook advertisement. We selected 22 seeds based on race/ethnicity and region of the United States to ensure that initial networks were diverse and not concentrated in a single region. The remainder of the sample was recruited through referral chains. The full sample $(\mathrm{N}=3,447)$ included $52 \%$ male respondents, with a racial breakdown of $70 \%$ white, 12\% Asian/Pacific Islander, 9\% Hispanic/ Latino, and 5\% black/African American. The majority of participants identified as heterosexual (93.9\%). The average age of participants was 20 (standard deviation $=1.77$ ) years, and more than half of the participants had completed some college education or more (66\%). On average, the respondents spent between 3 and 4 hours per day on the Internet, outside of school and work, and communicated with $47 \%$ of their contacts via phone or text message.

\section{Procedures}

Each prospective participant logged into the survey portal using a unique identifying number and completed a short eligibility screener. Eligible participants consented to the study and completed the survey. On average, the questionnaire took 37 minutes to complete. YAs received a VISA e-gift card for their participation (\$20) and an additional $\$ 10$ each for up to five additional YAs who they referred to the study and who completed the questionnaire. Data were protected with a 128-bit SSL encryption and kept on a secure server protected by firewall at the University of Michigan. Data quality checks were performed to circumvent duplicate and fraudulent entries $[14,15]$. The study was approved by the institutional review board of the University of Michigan.

\section{Measures}

Sexting. Respondents answered two questions regarding their lifetime sexting behavior. Using definitions provided by the Pew Internet and American Life Project [7], we asked participants whether they had ever sexted (i.e., sent a sexually suggestive nude or nearly nude photo or video of themselves to someone else) using their cell phones. Then, we asked whether they had ever received a sext (i.e., a sexually suggestive nude or nearly nude photo or video of someone else they know) on their cell phones. We created a lifetime sexting behavior status variable using four categories: (1) nonsexters, (2) senders, (3) receivers, and (4) two-way sexters.

Sexual behavior. Sexual (genital) experience was defined as oral sex: "any mouth to genital contact," vaginal sex: "male putting his penis in a female's vagina or a female putting a finger, dildo, or other object into another female's vagina," and anal sex: "male putting his penis into someone else's anus or female putting a finger, dildo, or other object into another female's anus." Two questions asked participants whether they "ever had sexual (genital) experiences with a male" and whether they "ever had sexual (genital) experiences with a female." Participants who answered yes to any of the questions were coded as "sexually 
active," whereas those who answered no to both questions were coded as "not sexually active." Sexually active youth reported the number of male and female partners they had in the past 30 days. We calculated the total number of sexual partners in past 30 days by adding the reported number for male and female partners. To distinguish lifetime sexual behavior from recent sexual behavior, we created a dichotomous variable $(0=$ no, $1=$ yes $)$ that identified whether respondents had one or more partners in the past 30 days. Participants also reported the number of unprotected sex partners in the past 30 days for vaginal sex and for anal sex. We calculated the proportion of unprotected sex partners by dividing participants' number of unprotected partners for vaginal sex and anal sex, respectively, by their total reported partners in the past 30 days. We used these proportions as indicators of sexual risk behavior.

Depression. Depressive symptoms in the past week were assessed using an 11-item short form of the Center for Epidemiologic Studies Depression scale [16,17]. We selected this short form to limit the number of survey items and reduce participant burden. Items (e.g., "I felt that everything I did was an effort") were scored on a four-point scale: 1 = rarely or none of the time ( $<1$ day), $4=$ most or all the time (5-7 days). Mean depression score was calculated by reverse scoring positively worded items (e.g., "I felt hopeful about the future") and creating a mean composite score. High scores indicated high depression symptoms in the past week $(\alpha=.82)$.

Anxiety. Anxiety symptoms were measured using the anxiety subscale of the Brief Symptom Inventory [18]. Participants reported how often in the past week they had experienced signs of anxiety, such as "nervousness or shakiness inside," using a 5 -point scale ( $1=$ never, 5 = very often). We computed a mean total anxiety score, where higher scores indicated higher anxiety symptoms $(\alpha=.90)$.

Self-esteem. We assessed self-esteem using the 10-item Rosenberg Self-Esteem Scale [19]. Participants responded to items (e.g., "I feel I have a number of good qualities") on a four-point scale ( 1 = strongly disagree, $4=$ strongly agree). We created a mean composite self-esteem score. Higher scores indicated higher self-esteem $(\alpha=.87)$.

Sociodemographic characteristics. Participants reported their biological sex, highest education level, and whether they were Hispanic/Latino, followed by their race/ethnicity. Participants also reported their sexual orientation (straight/heterosexual, gay/lesbian/homosexual, bisexual or other). We recoded sexual orientation into two categories: heterosexual and homo-/bisexual (other responses were excluded from the analysis, $n=5$ ). We calculated participant age by subtracting their month and year of birth from the date of study participation.

Internet use. Participants reported, on average, how many hours per day they spent on the Internet for personal use ( $1=$ no hours to $8=\geq 16$ hours).

Phone/texting communication. We asked participants how many YAs they had contact with in the past 3 months, and of those who they were in contact with, how many they usually communicated with via phone or text. We divided the number of phone/ text contacts by the total number of contacts in the past 3 months to compute a proportion of contacts phoned/texted.

\section{Data analytical approach}

Participants recruited through RDS are linked by their recruitment chains and are therefore correlated. We computed a statistical weight (RDS2) to correct for clustering that resulted from the network-referral procedures [20]. Using RDS2, the data are weighted by participants' network characteristics, such as the number of YAs whom the participants know, the proportion of youth with whom they interact with online, and racial homogeneity of their networks. After adjusting for these network-level intercorrelations with the RDS2 weights, our final analytical sample comprised 827 individuals.

We performed descriptive statistics for study variables on both the full $(n=3,447)$ and the weighted ( $n=827)$ samples and performed an attrition analysis for those with missing sexting data. All variables were normally distributed, except for the number of partners in the past 30 days (skewness $=15.6$ ); this variable was $\log$ transformed to correct for positive skew. In subsequent analyses, we weighted the RDS2 weight [20]. Data were analyzed in three steps. First, we used cross tabs to examine the intersection between sending and receiving a sext message, and to create sexting status categories. Second, we analyzed bivariate relationships between sexting status and variables of interest. For continuous variables, we used analysis of variance, with post hoc Scheffe tests to compare mean scores across sexting groups. We tested the association between sexting and categorical variables using $\chi^{2}$ tests and odds ratios (ORs). Third, we performed multinomial regression analysis that tested the relationship between sexting status and each sexual health outcome, depression, anxiety, and self-esteem, after accounting for all demographic variables, Internet use, and proportion of contacts phoned/texted. Multivariate and bivariate analysis results were the same for all predictors. For brevity, we report only bivariate and statistically significant results $(p<.05)$.

\section{Results}

\section{Attrition analyses}

Of the 827 respondents in the weighted sample, 760 (91.7\%) answered both questions on sexting, whereas 67 (8.3\%) had missing data for one or both of the sexting items. A greater percentage of male respondents (10.8\%) had missing data when compared with their female counterparts $\left(5.7 \%, \chi_{(1)}^{2}=6.9\right)$, and more non-sexually active participants (15\%) had missing data than their sexually active counterparts $\left(5.3 \%, \chi_{(1)}^{2}=21.6\right)$. Additionally, those with missing data had fewer sexual partners in the past 30 days (mean difference in log number of partners $=.15$, $t=3.15)$, a lower proportion of unprotected vaginal sex partners (mean difference $=.076, t=3.26$ ), and lower self-esteem (mean difference $=.17, t=2.32$ ) when compared with those who responded to both sexting questions. We found no differences by race, sexual orientation, age, education level, daily hours spent on the Internet, proportion of contacts phoned/texted, anxiety, or depression. Only participants with full sexting data available were included in analyses; demographic characteristics are displayed in Table 1. 
Table 1

Descriptives for participants included in analysis $(\mathrm{n}=760)$

\begin{tabular}{|c|c|c|}
\hline Variable & $\begin{array}{l}\text { Mean } \\
\text { (standard } \\
\text { deviation)/n (\%) }\end{array}$ & Range \\
\hline \multicolumn{3}{|l|}{ Sex } \\
\hline Male & $373(49.6 \%)$ & \\
\hline Female & $379(50.4 \%)$ & \\
\hline \multicolumn{3}{|l|}{ Race } \\
\hline Black/African American & $38(5.0 \%)$ & \\
\hline White & $527(70.4 \%)$ & \\
\hline Asian/Pacific Islander & $84(11.2 \%)$ & \\
\hline Hispanic/Latino & $66(8.9 \%)$ & \\
\hline Other & $34(4.5 \%)$ & \\
\hline \multicolumn{3}{|l|}{ Sexual orientation } \\
\hline Heterosexual & $708(93.8 \%)$ & \\
\hline Homo-/bisexual & $47(6.2 \%)$ & \\
\hline Age & $20.8(1.77)$ & \\
\hline Education & $3.57(1.28)$ & $0-6$ \\
\hline Daily Internet use & $3.88(1.27)$ & $1-8$ \\
\hline Proportion of contacts phoned/texted & $.50(.32)$ & $0-1$ \\
\hline \multicolumn{3}{|l|}{ Sexually active } \\
\hline Yes & $520(70.2 \%)$ & \\
\hline No & $221(29.8 \%)$ & \\
\hline \multicolumn{3}{|l|}{ Sexually active (past 30 days) } \\
\hline Yes & $349(52.9 \%)$ & \\
\hline No & $392(47.1 \%)$ & \\
\hline Natural Log of partners (past 30 days) ${ }^{a}$ & $.68(2.11)$ & \\
\hline $\begin{array}{l}\text { Proportion of unprotected vaginal sex } \\
\text { partners (past } 30 \text { days) }\end{array}$ & $.12(.24)$ & $0-1$ \\
\hline $\begin{array}{l}\text { Proportion of unprotected anal sex } \\
\text { partners (past } 30 \text { days) }\end{array}$ & $.30(.14)$ & $0-1$ \\
\hline Depression & $1.93(.53)$ & $1-4$ \\
\hline Anxiety & $1.90(.83)$ & $1-5$ \\
\hline Self-esteem & $3.05(.55)$ & $1-5$ \\
\hline \multicolumn{3}{|l|}{ Sent a sext } \\
\hline Yes & $229(30.1 \%)$ & \\
\hline No & $531(69.9 \%)$ & \\
\hline \multicolumn{3}{|l|}{ Received a sext } \\
\hline Yes & $310(40.8 \%)$ & \\
\hline No & $450(59.2 \%)$ & \\
\hline
\end{tabular}

a Among those sexually active in the past 30 days.

\section{Sexting behavior and demographics}

More than half (57\%) of the respondents were nonsexters, $28.2 \%$ were two-way sexters, $12.6 \%$ were receivers, and $2 \%$ were senders (Table 2). Owing to small cell size $(n=15)$, we excluded senders from subsequent analyses.

Results from bivariate analyses are presented in Table 3. Sexting behavior differed by $\operatorname{sex}\left(\chi_{(2)}^{2}=11.3, p<.05\right)$ and race/ethnicity $\left(\chi_{(8)}^{2}=31.4, p<.001\right)$. Male respondents were more likely to be receivers than their female counterparts ( OR $=2.2, p=.001)$, but we found no differences by sex for nonsexters or for two-way sexters. A greater number of Asian/ Pacific Islanders reported never sexting compared with other race/ethnicities. Compared with whites, Asian/Pacific Islanders showed five times greater odds of being a nonsexter than a two-way sexter $(\mathrm{OR}=5.4, p<.001)$. We found no differences in sexting behavior by age, sexual orientation, education, daily hours spent on the Internet, or proportion of contacts phoned/ texted.

\section{Sexting and sexual behavior}

We found an association between lifetime sexual activity and sexting behavior $\left(\chi_{(2)}^{2}=105, p<.001\right)$. Receivers were three times more likely to be sexually active $(\mathrm{OR}=3.2, p<.001)$ compared with nonsexters. Two-way sexters were 14 times more likely to report lifetime sexual activity $(\mathrm{OR}=14.3, p<.001)$ compared with non-sexters. Similarly, recent sexual activity, in the past 30 days, was also associated with sexting behavior $\left(\chi_{(2)}^{2}=76, p<.001\right)$. When we assessed only those respondents who reported being sexually active in the past 30 days, we found no association between sexting behavior and number of partners, proportion of unprotected vaginal sex, or proportion of unprotected anal sex partners.

\section{Sexting behavior and psychological well-being}

We found no differences across sexting groups in depression $\left(F_{2,714}=1.08, p=.34\right)$, anxiety $\left(F_{2,714}=.141, p=.87\right)$, or selfesteem $\left(F_{2,713}=.988, p=.37\right)$.

\section{Discussion}

We examined YAs' sexting behavior and its association with health. Our results indicate that sexting is a prevalent behavior among YAs, and show slightly higher rates of sending and receiving sexts than other recent findings [7]. We found that $30 \%$ of the YAs in our sample had sent a sext and $41 \%$ had received a sext, compared with $13 \%$ sending and $31 \%$ receiving sexts in the Lenhart study [7]. These differences may be attributable to age differences in the samples. Lenhart's findings focused on individuals aged 18-29 years, whereas our sample focused on those aged $18-24$ years. It is also possible that sexting is increasing owing to technological advances. Sending photos and videos via cell phones increased from 2010 to 2011 (36\%-54\%) [21], and it is plausible that sexting is following that trend. Longitudinal data are needed for us to know whether sexting is increasing among YAs. Our results also suggest that sexting is most often a reciprocal behavior. Among those participants who had ever sent or received a sext, $66 \%$ reported both sending and receiving sexts. Given findings that most young men and women report sharing sexts within a dating relationship [6,22], it is likely that our findings reflect sexting between romantic partners.

Similar to Lenhart [7], we found that young men are more likely than young women to receive a sext without sending one. These results could be attributed in part to young men receiving photos that were originally intended for someone else. Researchers have found that $40 \%$ of men (vs. $24 \%$ of women) reported receiving second-hand sext content, and that $14 \%$ of men had received a mass sext, whereas only $9 \%$ of women reported this $[5,6]$. When men receive forwarded sexts, they may not be a part of a reciprocal sexting relationship and therefore do not send contents in return. This finding may also reflect sexual objectification [23] being enacted through technology. Qualitative research may be warranted to obtain more in-depth information about this pattern of sexting behavior.

Table 2

Count and percentage of "ever sent a sext" crossed with "ever received a sext"

\begin{tabular}{llll}
\hline Sent a sext & \multicolumn{3}{l}{ Received a sext } \\
\cline { 2 - 4 } & No (\%) & Yes (\%) & Total (\%) \\
\hline No & $435(57.2)$ & $96(12.6)$ & $531(69.9)$ \\
Yes & $15(2.0)$ & $214(28.2)$ & $229(30.1)$ \\
Total & $450(59.2)$ & $310(40.8)$ & $760(100.0)$ \\
\hline
\end{tabular}


Table 3

Sexting status by demographics, sexual behavior, and psychological well-being

\begin{tabular}{|c|c|c|c|c|}
\hline \multirow[t]{2}{*}{ Variable } & \multicolumn{3}{|c|}{ Sexting status M (standard deviation)/n (\%) } & \multirow{2}{*}{$\begin{array}{l}\text { Tests of association } \\
\mathrm{F} / \chi^{2}(d f)\end{array}$} \\
\hline & Never & Receive only & Both & \\
\hline Sex & & & & $11.33(2)^{\mathrm{a}}$ \\
\hline Male & $205(55.4 \%)$ & $63(17.0 \%)$ & $102(27.6 \%)$ & \\
\hline Female & $224(61.0 \%)$ & $32(8.7 \%)$ & $111(30.2 \%)$ & \\
\hline Race & & & & $31.41(8)^{\mathrm{a}}$ \\
\hline Black/African American & $18(50.0 \%)$ & $4(11.1 \%)$ & $14(38.9 \%)$ & \\
\hline White & $290(56.2 \%)$ & $70(13.6 \%)$ & $156(30.2 \%)$ & \\
\hline Asian/Pacific Islander & $71(85.5 \%)$ & $5(6.0 \%)$ & $7(8.4 \%)$ & \\
\hline Hispanic/Latino & $31(47.7 \%)$ & $10(15.4 \%)$ & $24(36.9 \%)$ & \\
\hline Other & $18(56.3 \%)$ & $4(12.5 \%)$ & $10(31.3 \%)$ & \\
\hline Sexual orientation & & & & $2.64(2)$ \\
\hline Heterosexual & $409(58.9 \%)$ & $91(13.1 \%)$ & $194(28.0 \%)$ & \\
\hline Homo-/bisexual & $23(50.0 \%)$ & $5(10.9 \%)$ & $18(39.1 \%)$ & \\
\hline Age & $20.8(1.77)$ & $20.4(1.71)$ & $20.8(1.80)$ & $1.97(2,739)$ \\
\hline Education & $3.6(1.32)$ & $3.40(1.28)$ & $3.63(1.17)$ & $1.06(2,741)$ \\
\hline Daily Internet use & $3.9(1.25)$ & $3.95(1.30)$ & $3.91(1.27)$ & $.34(2,741)$ \\
\hline Proportion of contacts phoned/texted & $.48(.33)$ & $.52(.32)$ & $.52(.32)$ & $1.92(2,742)$ \\
\hline Sexually active & & & & $104.78(2)^{\mathrm{a}}$ \\
\hline Yes & $46.5 \%$ & $14.8 \%$ & $38.8 \%$ & \\
\hline No & $85.9 \%$ & $8.6 \%$ & $5.5 \%$ & \\
\hline Sexually active (past 30 days) & & & & $76.28(2)^{a}$ \\
\hline Yes & $42.4 \%$ & $14.4 \%$ & $43.2 \%$ & \\
\hline No & $72.6 \%$ & $11.4 \%$ & $16.0 \%$ & \\
\hline Natural Log partners (past 30 days) ${ }^{b}$ & $.76(.33)$ & $.81(.28)$ & $.81(.34)$ & $.74(2,338)$ \\
\hline Proportion of unprotected vaginal sex partners (past 30 days) ${ }^{\mathrm{b}}$ & $.24(.29)$ & $.25(.30)$ & $.3(.31)$ & $2.48(2,305)$ \\
\hline Proportion of unprotected anal sex partners (past 30 days) ${ }^{\mathrm{b}}$ & $.04(.17)$ & $.06(.17)$ & $.1(.23)$ & $2.47(2,336)$ \\
\hline Depression & $1.9(.53)$ & $1.9(.54)$ & $2.0(.55)$ & $1.08(2,714)$ \\
\hline Anxiety & $1.9(.81)$ & $1.9(.86)$ & $1.9(.83)$ & $.14(2,714)$ \\
\hline Self-esteem & $3.1(.55)$ & $3.1(.55)$ & $3.1(.55)$ & $.99(2,713)$ \\
\hline
\end{tabular}

a Significant at $\alpha=.05$.

b Among those sexually active in the past 30 days.

Our findings on the relationship between sexting and sexual behavior support the perspective that sexting is a part of YAs' sexual relationships, but is not necessarily correlated with riskier or safer behavior. Although some teens report sexting as a substitute for physical contact [2], this use for sexting may not be common among YAs. Consistent with other studies [5], we found that YAs who are sexually active are more likely to sext than those who are not sexually active. Two explanations for this finding are possible: (1) when sexting is used to flirt with potential partners, it may precede or initiate sexual relationships [6], or (2) sexually active YAs may engage in a range of sexual behavior, including sexting. Additional research is needed on sexting and sexual relationships, as our cross-sectional data do not address this debate. Although sexting is correlated with lifetime and 30-day sexual activity, our results suggest that this does not necessarily translate into risky behavior. Although some researchers argue that exposure to sexual images in traditional media (e.g., television, movies, and magazines) and new media may lead to sexual risk [8], we found that sexting was not associated with more sexual partners or a higher proportion of unprotected sex partners for either vaginal sex or anal sex in the past 30 days.

Researchers have proposed that mental health issues may be related to sexting $[4,9,12,13]$. Our findings suggest that sexting is not associated with depression, anxiety, or self-esteem. In our sample, YAs who sexted and those who did not sext reported similar outcomes for these mental health indicators. However, it is possible that sexting could be problematic under some conditions. Scholars argue that the lack of control after a sext is sent or pressure by sexual partners to sext may contribute to psycholog- ical distress and mental health concerns [2,3,5]. Media reports have noted that when a sext spreads to an unintended audience, it may create psychological distress and suicide intentions $[10,11]$. Given that our data do not address these specific situations, future research exploring pressure to sext or viral sexts will help identify when sexting may result in deleterious mental health outcomes.

Although our study is one of the first to examine the effects of sexting on YAs' well-being, several limitations of our study should be noted. First, this study was cross sectional and does not establish causal relationships between sexting and either sexual health or mental health. Nevertheless, our findings suggest that longitudinal research is warranted. Second, owing to our sampling methods, some racial and educational groups were underrepresented, and our results may not be generalizable to the YA population as a whole. Yet very few national studies of sexting and health correlates have been conducted, and our findings offer a more in-depth examination of this behavior than other studies on a national scale. Third, we were not able to include senders in our analysis. Although we were unable to examine whether senders were different from their counterparts, our results add to our understanding of this behavior by revealing that sending a sext without receiving in return may not be a common practice for YAs.

Our study introduces sexting behavior categories (nonsexters, receivers, senders and two-way sexters) as a way to conceptualize sexting. We provide an initial effort to examine sexting and its relationship with sexual risk behavior and psychological well-being, but further research is needed to provide a more in-depth understanding of this behavior. Qualitative research 
that examines relationship contexts and motivation for sexting has been published for the teen population [2] and is also needed for YAs. A richer understanding of whom sexts are sent to, or received from, and why YAs sext may help explain gender differences in sexting and add insight into the relationship between sexting and sexual behavior. We did not find a relationship between sexting and depression, anxiety, or self-esteem, but further research is needed to examine the association between sexting and mental health. As mentioned earlier in the text, pressure to sext and viral sexts may present mental health risks, but, to date, there are no studies that address these specific situations. Finally, our study included YAs only as young as 18 years of age, and we did not find age effects in any analysis. Nevertheless, individuals in their early and middle adolescence may have different health correlates with sexting because they are in a period of establishing a sexual identity [24]. Research on sexting including younger adolescents would be useful to see whether it influences sexual behaviors during this developmental period. Our results confirm that sexting is a prevalent behavior among YAs; however, we do not have enough information yet to inform health education programs or to determine whether sexting among YAs is a behavior that demands a share of public health's limited intervention resources. Future research in this area is warranted.

\section{Acknowledgments}

This research was funded by a research challenge grant from the National Institute of Drug Abuse (grant Number 5RC1DA028061-02; PI: Marc Zimmerman). J.A.B is supported by an NIH Career Development Award (K01-MH087242). The Prevention Research Center of Michigan is one of 37 institutions nationwide designated as a Prevention Research Center by the Centers for Disease Control. The authors have no conflicts of interest to declare.

\section{References}

[1] Chalfen R. It's only a picture: Sexting, "smutty" snapshots and felony charges. Vis Stud 2009;24:258-68.

[2] Lenhart A. Teens and Sexting. Pew Internet and American Life Project; 2009 Available at: http://pewinternet.org/Reports/2009/Teens-and-Sexting/ Overview/Findings.aspx. Accessed August 15, 2011.

[3] Diliberto GM, Mattey E. Sexting. NASN Sch Nurs 2009;24:263-7.
[4] Katzman DK. Sexting: Keeping teens safe and responsible in a technologically savvy world. Paediatr Child Health 2010;15:41-2.

[5] MTV, Associated Press: MTV-AP Digital Abuse Study. Available at: http://www.athinline.org/MTV-AP_Digital_Abuse_Study_Executive_Summary. pdf. Accessed August 15, 2011.

[6] National Campaign to Prevent Teen and Unwanted Pregnancy, Cosmogirl. com: Sex and Tech: Results of a Survey of Teens and Young Adults. Available at: http://www.thenationalcampaign.org/SEXTECH/PDF/SexTech_Summary. pdf. Accessed August 15, 2011.

[7] Lenhart A. Teens, Adults and Sexting: Data on sending and receipt of sexually suggestive nude or nearly nude images by Americans. Pew Internet and American Life Project; 2010. Available at: http://www.pewinternet.org/ Presentations/2010/Oct/Teens-Adults-and-Sexting.aspx. Accessed August 15, 2011.

[8] Brown JD, Keller S, Stern S. Sex, sexuality, sexting, and sexed: Adolescents and the media. Prev Res 2009;16:12.

[9] Chalfen R. Commentary sexting as adolescent social communication. J Child Media 2010;4:350-4

[10] Inbar M. "Sexting" bullying cited in teen's suicide. MSNBC.com. Available at: http://today.msnbc.msn.com/id/34236377/ns/today-today_ people/t/sexting-bullying-cited-teens-suicide/\#.TuluHdVQCdA. Accessed December 8, 2011

[11] Kranz C. Nude photo led to suicide. Cincinnati.com; 2009. Available at: http://news.cincinnati.com/article/20090322/NEWS01/903220312/Nudephoto-led-suicide. Accessed December 8, 2011.

[12] Reid DJ. Text or talk? Social anxiety, loneliness, and divergent preferences for cell phone use. Cyberpsychol Behav 2007;10:424-35.

[13] O'Keeffe GS, Clarke-Pearson K. Clinical report-The impact of social media on children, adolescents, and families. Pediatrics 2011;127:800-4.

[14] Bauermeister JA, Zimmerman MA, Johns MM, et al. Innovative recruitment using online networks: Lessons learned from an online study of alcohol and other drug use (AOD) using a web-based respondent drive sampling (webRDS) strategy. J Stud Alcohol Drugs (in press)

[15] Bauermeister JA, Pingel E, Zimmerman MA, et al. Data quality in web-based HIV/AIDS research: Handling invalid and suspicious data. Field Methods (in press).

[16] Radloff LS. The CES-D scale. Appl Psychol Meas 1977;1:385-401.

[17] Kohout FJ, Evans DA, Berkman LF, Cornoni-Huntley J. Two shorter forms of the CES-D depression symptoms index. J Aging Health 1993;5:179-93.

[18] Derogatis LR. The Brief Symptom Inventory. Baltimore, MD: Clinical Psychometric Research, 1975.

[19] Rosenberg M. Society and the Adolescent Self-Image. Princeton, NJ: Princeton University Press, 1965.

[20] Volz E, Heckathorn DD. Probability based estimation theory for respondent driven sampling. J Off Stat 2008;24:79.

[21] Smith A. Americans and their cell phones. Pew Internet and American Life Project, 2011. Available at: http://pewinternet.org/Reports/2011/CellPhones/Section-1/How-Americans-Use-Their-Cell-Phones.aspx.

[22] Weisskirch RS, Delevi R. "Sexting” and adult romantic attachment. Comput Hum Behav 2011;27:1697-701.

[23] Fredrickson BL, Roberts TA. Objectification theory-Toward understanding women's lived experiences and mental health risks. Psychol Women Q 1997;21:173-206.

[24] DeLamater J, Friedrich WN. Human sexual development. J Sex Res 2002;39: $10-4$. 